\title{
Avaliação qualitativa dos Centros de Referência Especializados de Assistência Social: gestão, organização e implementação dos serviços socioassistenciais
}

Cecilia Ishikawa Lariú ${ }^{1}$ Juliana França Varella ${ }^{2}$ Marco Antônio Carvalho Natalino ${ }^{3}$

Salete Da Dalt ${ }^{4}$

1 Especialista em Políticas Públicas e Gestão Governamental em exercício no Ministério do Desenvolvimento Social e Combate à Fome. Mestre em Gestão para o Desenvolvimento na London School of Economics.

2 Analista Técnica de Políticas Sociais em exercício no Ministério do Desenvolvimento Social e Combate à Fome. Mestranda em Antropologia Social pelo Departamento de Antropologia da Universidade de Brasília.

3 Coordenador Geral de Resultados e de Impactos em exercício no Ministério do Desenvolvimento Social e Combate à Fome. Mestre em Sociologia pela Universidade Federal do Rio Grande do Sul.

4 Coordenadora do Núcleo de Pesquisas, Informações e Políticas Públicas da Universidade Federal Fluminense (UFF) - DataUFF. Doutora em Avaliação de Política Social. 


\section{Resumo}

O PRESENTE TRABALHO APRESENTA OS RESULTADOS DO ESTUDO OUUALITATIVO SOBRE A GESTÃO, ORGANIZAÇÃO E IMPLEMENTAÇÃO DOS SERVIÇOS SOCIOASSISTENCIAIS DESENVOLVIDOS NOS CENTROS DE REFERÊNCIA ESPECIALIZADOS DE ASSISTÊNCIA SOCIAL (CREAS), EM ESPECIAL O Paefi (Serviço de Proteção e Atendimento ESPECIALIZADO A FAMÍLIAS E INDIVÍDUOS), O SERVIÇO ESPECIALIZADO EM ABORDAGEM SOCIAL E O Serviço de Proteção Social a Adolescentes EM CUMPRIMENTO de MEDIDAS SOCIOEDUCATIVAS. A PESOUUISA FOI REALIZADA PELO MINISTÉRIO do DeSEnVolvimento SOCIAL E Combate À FOME COM OS TÉCNICOS E USUÁRIOS DO EOUUIPAMENTO, COM O OBJETIVO DE FORNECER INFORMAÇÕES OUUE POSSAM SUBSIDIAR A GESTÃO DOS SERVIÇOS NO APERFEIÇOAMENTO DA PRESTAÇÃO DESTES. ESTA PESOUUISA REVELOU OUE OS CREAS ANALISADOS ESTÃO INSERIDOS EM UM AMBIENTE NO OUUAL O SISTEMA ÚNICO DE ASSISTÊNCIA SOCIAL (SUAS) É UMA REALIDADE CONHECIDA, OS SERVIÇOS DE MANEIRA GERAL SÃO PRESTADOS; NO ENTANTO, HÁ AINDA UMA SÉRIE DE DESAFIOS A SEREM ENFRENTADOS NO OUUE SE REFERE À GESTÃO E EXECUÇÃO DOS SERVIIÇOS, RECURSOS HUMANOS, CAPACITAÇÃO DOS PROFISSIONAIS, ENCAMINHAMENTOS DOS USUÁRIOS, ARTICULAÇÃO COM A REDE DA ASSISTÊNCIA SOCIAL E OUTRAS POLÍTICAS PÚBLICAS.

\begin{abstract}
THIS PAPER PRESENTS THE RESULTS OF A QUALITATIVE STUDY ON THE MANAGEMENT, ORGANIZATION AND IMPLEMENTATION OF SOCIAL ASSISTANCE SERVICES DEVELOPED IN SPECIALIZED RefERENCE CENTERS for SOCIAL AsSistance (CREAS), especially PAEFI (PRoteCtive SeRVICES AND SPECIALIZED Care to Families and Individuals), Specialized Service Approach in Social Service (Abordagem Social) and Social Protection of TeEns in Socio-Educational Measures (Medidas Socioeducativas). The surVEey waS CONDUCtED by the MINISTRY OF SOCIAL DEVELOPMENT AND FIGHT AGAINST HUNGER WITH THE TECHNICIANS AND USERS OF THE SERVICES, WITH THE GOAL OF PROVIDING INFORMATION THAT CAN SUPPORT THE MANAGEMENT OF SERVICES DELIVERY. THE SURVEY REVEALED THAT CREAS ANALYZED ARE PLACED IN AN ENVIRONMENT IN WHICH THE UNIFIED SOCIAL ASSISTANCE SYSTEM (SUAS) IS A KNOWN REALITY, THE SERVICES GENERALLY ARE PROVIDED; HOWEVER, THERE ARE STILL A NUMBER OF CHALLENGES TO BE ADDRESSED WITH REGARD TO THE MANAGEMENT AND DELIVERY OF SERVICES, HUMAN RESOURCES, TRAINING OF PROFESSIONALS, NETWORK WITH OTHER SOCIAL ASSISTANCE SERVICES AND OTHER PUBLIC POLICIES.
\end{abstract}

\section{PALAVRAS-CHAVE:}

gestão; assistência social; proteção social especial; CREAS; Paefi; abordagem social; medidas socioeducativas.

Revista Brasileira de Monitoramento e Avaliação | Número 7 | Janeiro-Junho de 2014 


\section{Introdução}

A Lei Orgânica da Assistência Social (LOAS) estabelece que a assistência social constitui-se como política não contributiva de seguridade social, realizada mediante um conjunto integrado de ações de iniciativa pública e da sociedade, tendo como objetivos a proteção social, a vigilância socioassistencial e a defesa de direitos. Tal lei também tem por princípio a universalização dos direitos sociais, garantindo o acesso do usuário da assistência às políticas públicas, respeitando sua dignidade e autonomia, divulgando amplamente os benefícios, serviços, programas e projetos assistenciais ofertados pelo poder público e os critérios para sua concessão.

No que se refere à proteção social, primeiro objetivo da política de assistência, visa à garantia da vida, à redução de danos e à prevenção da incidência de riscos, com especial atenção à família e a grupos com vulnerabilidades específicas, tais como crianças, adolescentes, idosos e pessoas com deficiência. A depender da situação de risco pessoal ou social - por exemplo, rompimento dos vínculos familiares, abuso sexual, violência física ou psicológica se caracterizam como situações de violações de direitos que requerem ações especiais de proteção social, com caráter protetivo.

Em um contexto de reordenamento da oferta de serviços sociassistenciais pelo poder público, foi aprovada a Lei n. 12.435/2011, que altera a LOAS, legislando sobre os conceitos de proteção social básica e especial e definindo os equipamentos públicos aptos a ofertar serviços socioassistenciais. A proteção social especial é formada pelo conjunto de serviços, programas e projetos que tem por objetivo contribuir para a reconstrução de vínculos familiares e comunitários, o fortalecimento das potencialidades e aquisições e a proteção de famílias e indivíduos no enfrentamento das situações de violação de direitos. Tal proteção se subdivide em proteção social de média complexidade - abrangendo ações de apoio sociofamiliar, abordagem de rua, medidas socioeducativas sem privação de liberdade, serviços de reabilitação para pessoas com deficiência e cuidados em domicílio - e proteção social de alta complexidade, que abarca ações de proteção integral para famílias e indivíduos em situação de abandono e que necessitam de acolhimento com acesso à moradia, alimentação etc.

No âmbito deste reordenamento, estabeleceu-se um equipamento público de referência para os serviços de proteção social de média complexidade. O Centro de Referência Especializado de Assistência Social (CREAS) é a unidade pública destinada à prestação de serviços a indivíduos e famílias que se encontram em situação de risco pessoal ou social, por violação de direitos ou contingência, que demandam intervenções especializadas da proteção social especial. Estes centros, instituídos no âmbito do Sistema Único de Assistência Social (SUAS), articulam, coordenam e ofertam serviços, programas, projetos e bene- 
fícios da assistência social, além de possuírem interface com as demais políticas públicas. Suas instalações devem ser compatíveis com os serviços nele ofertados, com espaços para trabalhos em grupo e ambientes específicos para recepção e atendimento reservado das famílias e indivíduos, assegurada a acessibilidade às pessoas idosas e com deficiência.

O principal serviço ofertado no âmbito do CREAS é o Paefi (Serviço de Proteção e Atendimento Especializado a Famílias e Indivíduos), que consiste no apoio, orientação e acompanhamento a famílias e indivíduos em situação de ameaça ou violação de direitos, articulando os serviços socioassistenciais com as diversas políticas públicas e com órgãos do sistema de garantia de direitos. Outro serviço ofertado pelos CREAS e analisado pela pesquisa é o Serviço Especializado em Abordagem Social, que tem como finalidade assegurar o trabalho social de abordagem, buscando ativamente a identificação, nos territórios, da incidência de trabalho infantil, exploração sexual de crianças e adolescentes, situação de rua, dentre outras. Por fim, a pesquisa avaliou a implementação do Serviço de Proteção Social a Adolescentes em Cumprimento de Medida Socioeducativa de Liberdade Assistida e de Prestação de Serviços à Comunidade no âmbito dos CREAS. Este serviço tem possui o objetivo de prover atenção socioassistencial e acompanhamento a adolescentes e jovens em cumprimento de medidas socioeducativas em meio aberto, determinadas judicialmente.

Em 2009, havia 1.239 CREAS no território nacional5. Após amplo processo de expansão dos serviços socioassistenciais, induzida pelo MDS em 2010, observou-se que, em 2013. havia 2.229 CREAS em 2.032 municípios $^{6}$. Este ganho de escala veio acompanhado de uma virtual universalização do equipamento em municípios de mais de 100 mil habitantes e de um expressivo aumento no número de municípios de menor porte com este equipamento público, como demonstra o Gráfico 1.

Assim, é possível afirmar que a progressiva institucionalização do SUAS que se observou no último decênio foi acompanhada de vigorosa expansão dos equipamentos

$5 \quad$ IBGE, 2009.

6 IBGE, 2013.

Revista Brasileira de Monitoramento e Avaliação | Número 7 | Janeiro-Junho de 2014 


\section{FIGURA 1: SÍNTESE DA AVALIAÇÃO PARCIAL DOS INDICADORES DO PPA \\ 2012-2015}

- 20092013

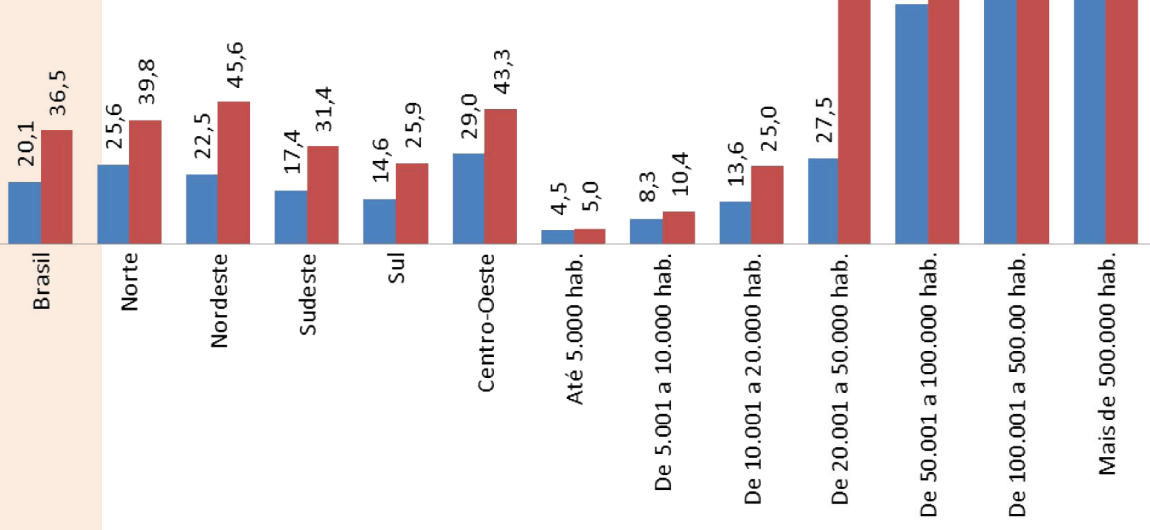

Fonte: IBGE, 2014

públicos e dos serviços socioassistenciais de proteção social especial de média complexidade. Esta expansão indicou, por sua vez, a pertinência da realização de uma pesquisa que possibilite melhor avaliar o processo de realização deste reordenamento e expansão, aprofundando o conhecimento gerado por dados quantitativos censitários, elaborados pela Pesquisa de Informações Básicas Municipais (Munic), bem como pelo Censo SUAS, mediante um estudo empírico in loco que permitisse uma avaliação qualitativa das práticas e percepções dos diversos agentes sociais - gestão municipal, equipe dos CREAS, usuários dos serviços e rede socioassistencial - envolvidos no fazer cotidiano destes equipamentos da assistência social.

Dessa forma, o presente artigo conta, para além desta introdução, com outras duas se- metodologia da pesquisa avaliativa realizada, enfatizando seu papel de auxílio ao aprimoramento da política pública, e a segunda mostra os resultados da pesquisa em si. Optou-se por dar maior foco às questões gerais de gestão do CREAS que permeiam os serviços ofertados, entretanto, sem deixar de apontar questões específicas de cada serviço no que se refere à execução bem como às percepções dos usuários.

\section{Metodologia}

Os objetivos específicos da pesquisa foram identificar e analisar:

- Estrutura administrativa municipal;

- Organização e gestão dos serviços do CREAS;

- Relação entre o CREAS (serviços oferta- 
dos) e o órgão gestor municipal da política de assistência social;

- Provisões (estrutura física, recursos materiais e socioeducativos);

- Recursos Humanos disponíveis para os serviços;

- Metodologias utilizadas nos atendimentos e acompanhamentos realizados (Paefi, Abordagem Social e MSE);

- Perfil das famílias e indivíduos atendidos e acompanhados;

- Principais dificuldades e potencialidades relacionadas à implementação dos serviços;
- Percepção dos técnicos e usuários sobre serviços prestados e acerca das aquisições dos usuários a partir das ações desenvolvidas nos serviços;

- Relação dos CREAS com outros atores (rede socioassistencial, órgãos de defesa de direitos e responsabilização, órgãos das demais políticas setoriais);

- Implantação efetiva dos serviços ofertados nos CREAS a partir das normatizações existentes.

Para alcançar os objetivos esperados, realizou-se uma pesquisa qualitativa baseada em análise de ambiência e coleta de dados com os atores-chave responsáveis pela organização e oferta dos serviços nas

\section{- OUADRO 1: REFERÊNCIA DOS MUNICÍPIOS SELECIONADOS E EFETIVAMENTE ESTUDADOS}

\begin{tabular}{|c|c|c|c|c|c|}
\hline $\begin{array}{l}\text { GRANDE } \\
\text { REGIÃOO }\end{array}$ & $\begin{array}{l}\text { PORTE POPU- } \\
\text { LACIONAL COM } \\
\text { MAIOR MÉDIA DE } \\
\text { CASOS ATENDI- } \\
\text { DOS NO PAEFI } \\
\text { PELAS UNIDADES } \\
\text { EM } 2010\end{array}$ & $\begin{array}{l}\text { MUNICÍPIOS ESTU- } \\
\text { DADOS }\end{array}$ & N. DE CREAS & $\begin{array}{c}\text { N. DE CASOS } \\
\text { ATENDIDOS NO } \\
\text { PAEFI }\end{array}$ & $\begin{array}{l}\text { MUNICÍPIOS } \\
\text { COM SERVIÇO } \\
\text { SENTINELA } \\
\text { ANTES DA } \\
\text { EXPANSÃO DE } \\
2005\end{array}$ \\
\hline \multirow{2}{*}{ NORTE } & Médio & Tabatinga - AM & 1 & 1.170 & Sim \\
\hline & Pequeno Porte I & Pacaraima - RR & 1 & 1.327 & Sim \\
\hline \multirow[t]{2}{*}{ NORDESTE } & Médio & $\begin{array}{l}\text { Santa Cruz do Capi- } \\
\text { baribe - PE }\end{array}$ & 2 & 3.744 & Sim \\
\hline & Metrópole & Fortaleza - CE & 2 & 4.952 & Sim \\
\hline \multirow{2}{*}{ SUDESTE } & Grande & Itaquaquecetuba -SP & 1 & 1.435 & Não \\
\hline & Metrópole & Rio de Janeiro - RJ & 9 & 11.584 & Sim \\
\hline \multirow{2}{*}{ SUL } & Pequeno Porte I & Nova Tebas - PR & 1 & 1.076 & Não \\
\hline & Metrópole & Curitiba - PR & 10 & 11.691 & Sim \\
\hline \multirow{2}{*}{ CENTRO-OESTE } & Pequeno Porte II & Paranaíba-MS & 1 & 1.268 & Não \\
\hline & Grande & Cuiabá - MT & 1 & 2.968 & Não \\
\hline
\end{tabular}

Fonte: DataUFF/fevereiro de 2014

Revista Brasileira de Monitoramento e Avaliação | Número 7 | Janeiro-Junho de 2014 
unidades do CREAS e aos usuários desses serviços, utilizando-se da realização de entrevistas em profundidade e de grupos focais.

A amostra foi selecionada com objetivo de contemplar todas as regiões e portes municipais. Garantida a diversidade regional e de porte, a seleção obedeceu aos seguintes critérios: média dos casos (indivíduos e famílias) assistidos pelo Paefi em 2010; execução dos três serviços (Paefi, MSE e SEAS); tempo de implantação do equipamento, buscando contemplar municípios que implantaram o Programa Sentinela até 2005 e os que implantaram o CREAS após esse período. Destes critérios resultou a seleção de 10 municípios, conforme Quadro 1.

\section{- OUADRO 2: OUUADRO SÍNTESE - NÚMERO DE ENTREVISTAS E GRUPOS FOCAIS POR MUNICÍPIO}

\begin{tabular}{|c|c|c|c|c|c|c|c|c|c|c|}
\hline ENTREVISTADO & $\begin{array}{l}\text { TABA- } \\
\text { TINGA } \\
\text { - AM }\end{array}$ & $\begin{array}{l}\text { PACA- } \\
\text { RAIMA } \\
- \text { RR }\end{array}$ & $\begin{array}{l}\text { SANTA } \\
\text { CRUZ } \\
\text { DO CA- } \\
\text { PIBARIBE } \\
\text { - PE }\end{array}$ & $\begin{array}{l}\text { FORTA- } \\
\text { LEZA } \\
\text { - CE }\end{array}$ & $\begin{array}{l}\text { ITAQUA- } \\
\text { QUECE- } \\
\text { TUBA } \\
\text {-SP }\end{array}$ & $\begin{array}{l}\text { RIO DE } \\
\text { JANEI- } \\
\text { RO - RJ }\end{array}$ & $\begin{array}{l}\text { NOVA } \\
\text { TEBAS } \\
\text { - PR }\end{array}$ & $\begin{array}{l}\text { CURITI- } \\
\text { BA - PR }\end{array}$ & $\begin{array}{l}\text { PARA- } \\
\text { NAÍBA } \\
\text { - MS }\end{array}$ & $\begin{array}{l}\text { CUIABÁ } \\
\text { - MT }\end{array}$ \\
\hline $\begin{array}{l}\text { Responsável } \\
\text { Municipal pela } \\
\text { Proteção So- } \\
\text { cial Especial }\end{array}$ & 1 & 1 & 1 & 1 & 1 & 1 & 1 & 1 & 1 & 1 \\
\hline $\begin{array}{l}\text { Coordenador } \\
\text { do CREAS }\end{array}$ & 1 & 0 & 1 & 1 & 1 & 1 & 1 & 1 & 0 & 1 \\
\hline $\begin{array}{l}\text { Assistente } \\
\text { Social }\end{array}$ & 1 & 1 & 1 & 1 & 1 & 1 & 1 & 1 & 1 & 1 \\
\hline Psicólogo & 1 & 1 & 1 & 1 & 1 & 1 & 1 & 1 & 1 & 1 \\
\hline Advogado & 0 & 0 & 1 & 0 & 1 & 1 & 0 & 0 & 1 & 1 \\
\hline $\begin{array}{l}\text { Profissional } \\
\text { responsável } \\
\text { pela aborda- } \\
\text { gem social }\end{array}$ & 1 & 1 & 1 & 1 & 1 & 1 & 1 & 1 & 1 & 1 \\
\hline $\begin{array}{l}\text { Profissional } \\
\text { responsável } \\
\text { por LA e PSC }\end{array}$ & 1 & 1 & 0 & 2 & 1 & 1 & 1 & 1 & 0 & 1 \\
\hline $\begin{array}{l}\text { Usuários Paefi } \\
\text { e abordagem } \\
\text { social (em } \\
\text { grupo focal) }\end{array}$ & 8 & 10 & 6 & 5 & 9 & 9 & 11 & 7 & 7 & 0 \\
\hline $\begin{array}{l}\text { Usuários LA } \\
\text { e PSC }\end{array}$ & 2 & 3 & 3 & 6 & 5 & 5 & 3 & 5 & 2 & 5 \\
\hline
\end{tabular}




\section{GRÁFICO 2: SÍNTESE ESTRUTURA ASSISTÊNCIA SOCIAL NOS MUNICÍPIOS}

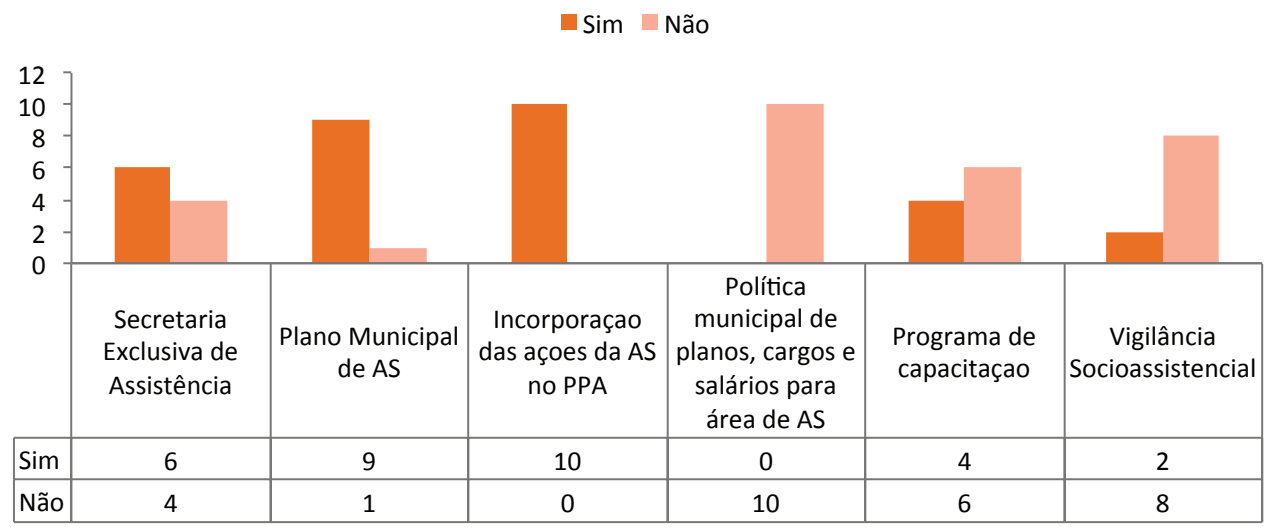

Fonte: IBGE, 2014

A pesquisa de campo foi executada entre os meses de agosto e outubro de 2013. Foram realizadas, em todos os 10 municípios, entrevistas em profundidade com gestores, coordenadores e técnicos das unidades que buscaram mapear a situação atual dos CREAS no que se refere à organização, gestão, implementação dos serviços ofertados e relações existentes com a Rede Socioassistencial e as Políticas Setoriais. Também foram realizadas entrevistas individuais com jovens em cumprimento de MSE e Grupos Focais formados por usuários do Paefi e/ou Abordagem Social escolhidos aleatoriamente a partir dos registros de atendimento, totalizando 62 profissionais e 111 usuários entrevistados. Devido à diversidade de situações observadas em campo, o número de entrevistas por município sofreu pequena variação, conforme resumido no Quadro 2 ao lado.

Complementarmente, foram realizadas 40 horas de análise de ambiência em cada um dos equipamentos que compõem a amostra. Por meio desta técnica foram elaborados "diários de campo" com as impressões obtidas por meio de conversa ou observações sobre o dia a dia da execução dos serviços. Para garantir maior objetividade, as entrevistas e a ambiência obedeceram a roteiros predefinidos, construídos conjuntamente pela DataUFF e as equipes da Secretaria Nacional de Assistência Social (SNAS) e da Secretaria de Avaliação e Gestão da Informação (SAGI).

Revista Brasileira de Monitoramento e Avaliação | Número 7 | Janeiro-Junho de 2014 


\section{Sistematização de resultados}

\section{ASSISTÊNCIA SOCIAL NOS MUNICÍPIOS}

Em termos institucionais, os CREAS analisados estão inseridos em um ambiente similar à situação observada no território nacional como um todo, no qual o SUAS é uma realidade conhecida; no entanto, os avanços propostos em seu bojo ainda não foram satisfatoriamente incorporados. Em consonância com o incipiente cenário observado no Censo SUAS (2013) no que diz respeito à área de Gestão do Trabalho (apenas $31,1 \%$ de formalização por meio de subdivisão administrativa), praticamente não há, nos municípios investigados, uma política municipal de planos, cargos e salários e um programa de capacitação para área de Assistência Social - temas regulamentados pela NOB-SUAS-RH -, como sintetizado no Gráfico acima:

Seis dos dez municípios investigados possuem uma pasta exclusiva da Assistência Social, dado um pouco abaixo da média nacional de $79 \%$ observada no Censo SUAS (2013). Nove municípios possuem Plano Municipal de Assistência Social, e todos incorporam ações da Assistência Social em seu Plano Plurianual. Constata-se, portanto, que tais secretarias respondem às exigências básicas da Política Nacional de Assistência Social. Entretanto, as três variáveis seguintes indicam que estas Secretarias não apresentam avanços significativos nos elementos incorporados a esta política nos últimos anos
(Plano de carreira, Capacitação7 e Vigilância Socioassistencial).

Embora nove dos dez municípios pesquisados indicassem a existência do Plano Municipal de Assistência Social, foi verificado que para alguns municípios não há acompanhamento e nem uma periodicidade para a sua realização. Não há, via de regra, produção e sistematização de informações territorializadas sobre as situações de vulnerabilidade e risco que incidem sobre famílias e indivíduos, de maneira a propiciar uma atuação proativa ou mesmo preventiva dos serviços. Nos municípios de pequeno e médio porte identifica-se, na verdade, certo desconhecimento acerca da área de vigilância social.

Com efeito, o entendimento da vigilância e o seu desenvolvimento foi verificado basicamente nas metrópoles, enquanto nos municípios de menor porte o tema apresentou-se de forma bastante embrionária, quando não inexistente. Há o registro das informações acerca da vulnerabilidade e dos riscos dos indivíduos de maneira informal, não sistematizada, a partir dos próprios atendimentos que chegam ao equipamento, com base nos quais os técnicos vão concluindo em qual região há maior incidência de determinadas situações de risco. Essa prática configura uma gestão que se baseia na síntese pela experiência. Não foi observada análise estratégica e proativa, que contribuiria para a vigilância dos padrões e serviços, indicando as necessidades de proteção da população e as características 
e distribuição da rede de proteção social instalada para a oferta de serviços. Considerando a vigilância como uma área de gestão da informação dedicada a apoiar as atividades de planejamento, supervisão e execução dos serviços socioassistenciais, a elaboração do planejamento da assistência social no município, por sua vez, vê-se prejudicada por esta carência diagnóstica. É importante notar que devido à natureza das violações de direito que os CREAS atendem, a exemplo dos casos de violência intrafamiliar e comunitária, imagina-se que algumas situações não cheguem aos equipamentos de forma espontânea, de modo que a vigilância socioassistencial se constitui como estratégia fundamental para que se conheça a demanda real de uma localidade. Portanto, a não realização da vigilância, ligada à falta de conhecimento dos profissionais dos equipamentos, bem como à sobrecarga de trabalho, que os faz se voltarem para as demandas mais urgentes que surgem cotidianamente, pode prejudicar muito a quantificação e qualificação da demanda existente pelos serviços que o CREAS desenvolve e, logo, prejudicar o processo de planejamento das ações, levando a demonstrações equivocadas acerca da cobertura e da qualidade dos serviços ofertados.
Nesse sentido, faz-se necessário fazer a distinção entre o planejamento mais geral, estratégico da política de assistência social municipal, que leva em consideração um diagnóstico socioterritorial e os insumos da vigilância realizada no território, e o planejamento mais cotidiano dos profissionais que se organizam de maneira a atender a demanda no equipamento. Fica claro que o entendimento do planejamento é certamente influenciado pelo lócus de atuação do profissional. Quando indagados, normalmente os coordenadores da PSE entenderam o planejamento como mais amplo, estratégico, enquanto os coordenadores do CREAS e principalmente os técnicos tratam o planejamento como um plano de ação para atendimento no curto prazo das demandas do equipamento, o qual nem sempre se revela de forma proativa.

Ainda, o que se verifica é que o Coordenador da Proteção Social Especial e/ou o Coordenador do CREAS nos municípios, pelo fato de possuírem maior contato com o órgão gestor da Assistência Social, conhecem o diagnóstico socioterritorial ou o planejamento da política, quando existentes, ao passo que, à medida que nos distanciamos dos cargos de coordenação e nos aproximamos mais dos

7 A variável "existência de programa de capacitação" foi interpretada de forma bastante flexível pelos/as entrevistados e, portanto, pode significar tanto a existência de uma subárea específica de formação de profissional quanto uma decisão institucional de se apoiar os processos de capacitação, facilitando a participação de seus técnicos em eventos realizados pelo Governo do estado ou outros atores.

Revista Brasileira de Monitoramento e Avaliação | Número 7 | Janeiro-Junho de 2014 
profissionais, técnicos dos equipamentos, esse conhecimento se perde, configurando uma situação de assimetria de informação. $\mathrm{Na}$ maioria das vezes, os técnicos do CREAS não participam do planejamento mais amplo da Assistência Social, sendo envolvidos apenas no planejamento mais cotidiano da atuação no equipamento.

Relatos significativos apontam que a falta de planejamento correlaciona-se à sobrecarga das equipes, ao descompasso entre o Plano Plurianual 2009-2013, elaborado pela gestão anterior, e as prioridades da nova gestão municipal. A percepção generalizada entre os entrevistados indica que a demanda é grande e que os equipamentos são em pouca quantidade. Entretanto, dado que tal percepção está baseada na experiência cotidiana e não contempla uma avaliação de demanda baseada em indicadores mais sólidos, não se pode depreender estimativas do número de equipamentos e profissionais necessários para atender à demanda no território por serviços de proteção social especial de média complexidade, resultando num enfraquecimento técnico dos pleitos orçamentários da área de assistência social.

\section{RELAÇÕES ENTRE CREAS E ÓRGÃO GESTOR}

É rara a existência de uma relação de proximidade entre o órgão gestor e o CREAS. Há o consenso em todos os municípios investigados quanto ao insuficiente suporte técnico e de materiais recebido. Um depoimento significativo aponta a falta de acompanhamento, monitoramento e apoio para ajudar a decidir encaminhamentos.

Foi citado por uma profissional do CREAS que apenas a lei é o que há de suporte técnico, que não há discussão e, em suas palavras, "apropriação desses instrumentais". Nenhum dos entrevistados mencionou algum processo de monitoramento ou supervisão que seja realizado pelo órgão gestor que sirva de apoio ou suporte à execução dos serviços. Na maioria dos casos, a relação entre o CREAS e o órgão gestor municipal da assistência social é formal, obedecendo às hierarquias e mediada pelo coordenador do equipamento, com pouca ou nenhuma participação da equipe técnica. Faltam também reuniões regulares entre o órgão gestor e a equipe do CREAS. Os profissionais que atuam diretamente com as MSE são os que mais claramente se queixam desta falta de apoio institucional e técnico por parte do órgão gestor, agravando-se, assim, a situação de dependência para com os órgãos do Judiciário.

O porte do município pode ser considerado um dos elementos que influencia no padrão de relação - mas não como elemento determinante. Isto porque em municípios menores, a própria estrutura aproxima gestores e técnicos. Entretanto, esta proximidade não garante eficácia e eficiência do trabalho, ou mesmo a satisfação das equipes. 0 que aparece nos discursos como fundamental é que o órgão gestor ofereça acompanhamento técnico, recursos materiais necessários e, sobretudo, retaguarda institucional nas articulações e para decisões necessárias na garantia dos direitos socioassistenciais dos/as usuários/as. 


\section{GESTÃO DOS CREAS}

Os CREAS analisados se caracterizam por certa debilidade nos processos de planejamento, monitoramento, avaliação e sistematização da execução realizada. A avaliação, tal qual o planejamento, caracteriza-se como um processo caseiro, informal e pontual.

Há um organizado sistema de registro de casos e atividades em todas as cidades visitadas - independente do instrumento que se utilize. Contudo, embora todos reconheçam a importância de se contar com instrumentos completos e digam que os dados auxiliam no planejamento das ações, não se verificou em nenhum município o tratamento desses dados e, consequentemente, produção de informação. Com efeito, não foi identificada qualquer prática que possa ser classificada como um esforço de monitoramento, mesmo quando se verifica o desempenho com relação aos resultados previstos, comparando e analisando as tendências ao longo do tempo.

O cenário aponta dificuldades comuns aos serviços como os realizados pelos CREAS: com altas demandas de risco e vulnerabilidades, parece ser difícil encontrar momentos para "parar" a execução. As "urgências" do dia a dia tendem a ocupar todo o tempo de trabalho e momentos para planejar, monitorar e avaliar são entendidos, muitas vezes, como tarefas burocráticas concorrentes à execução dos serviços, sendo que esta não pode esperar. Conclui-se que, nos municípios pesquisados, em especial nos de menor porte, a gestão do CREAS está centrada no atendimento urgente das demandas, e que o planejamento é voltado principalmente para o curto prazo, de maneira a organizar a atuação dos profissionais frente à demanda do equipamento. Não há, de maneira geral, uma reflexão estratégica a partir de um diagnóstico socioterritorial e das ações de vigilância, que norteiem a atuação no médio e longo prazos.

A esse respeito, observou-se também que o princípio da divulgação ampla dos benefícios, serviços, programas e projetos assistenciais, consubstanciado na Lei Orgânica da Assistência Social (e do qual a identificação por placa do CREAS, citada na seção seguinte, pode ser considerada um indicador mínimo) não é uma prioridade. O trabalho cotidiano dos CREAS se mostrou marcado pelo atendimento de muitas situações complexas e urgentes para as quais o corpo técnico disponível busca responder dentro da sua capacidade, dando insuficiente atenção para atividades relacionadas à divulgação do serviço, ao acolhimeneto e ao estudo mais sistemático das situações presentes no território coberto pelo equipamento.

Revista Brasileira de Monitoramento e Avaliação | Número 7 | Janeiro-Junho de 2014 


\title{
- GRÁFICO 3: PROFISSIONAIS PESOQUISADOS: FORMAÇÃO UNIVERSITÁRIA
}

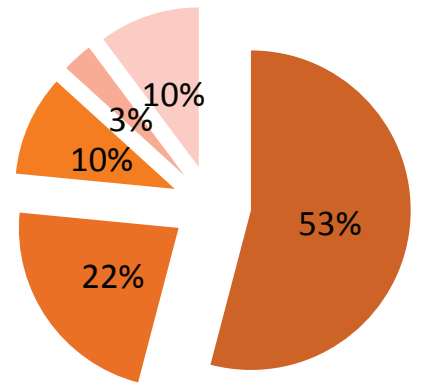

\author{
- Serviço Social \\ Psicologia \\ Direito \\ Pedagogia \\ Outros
}

Fonte: IBGE, 2014

Pela própria natureza das situações atendidas nos CREAS, que envolvem pessoas fragilizadas por situações de violência, abuso e exploração, amiúde perpetradas por familiares, é imprescindível que seja dado maior ênfase a que o espaço do CREAS, desde a sua ambiência física até a forma de atendimento por seus profissionais, caracterize-se como acolhedor, capaz de ouvir com sensibilidade e privacidade àqueles que o procuram espontaneamente.

Além disso, torna-se necessário que o espaço seja melhor publicizado, de forma que a comunidade em sua área de atuação tome conhecimento do seu papel. Neste tocante, o equipamento CREAS é bastante distinto dos CRAS, cujo conhecimento é maior entre a população por conta de sua maior penetração territorial e dos serviços e programas de grande visibilidade aos quais ele dá acesso (a exemplo do Programa Bolsa Família). Também é importante perceber que, neste quesito, a assistência social distancia-se de outras políticas sociais como as de saúde, uma vez que não há falta de conhecimento por parte da

população de que - independentemente da nomeação dada - os problemas de saúde de média complexidade são atendidos em hospitais, policlínicas e ambulatórios ${ }^{8}$.

\section{ESTRUTURA FÍSICA}

Os dados acerca das provisões dos CREAS foram captados, sobretudo, dos relatos de ambiência e de discursos dos profissionais, que estavam interessados em relatar o que faltava. Praticamente todos os equipamentos necessitam de ajustes para se adequar ao exigido pela Tipificação Nacional dos Serviços Socioassistenciais no que se refere, sobretudo, às normas de acessibilidade conforme ABNT, aos recursos materiais e aos materiais socioeducativos. Grande parte dos CREAS visitados possui placa de sinalização na entrada. Por outro lado, como apontado anteriormente, na maioria dos casos a recepção dos equipamentos é inadequada às necessidades da política pensada para o CREAS, tendendo estes ambientes a não garantirem a privacidade e a não serem acolhedores. 


\section{- GRÁFICO 4: PROFISSIONAIS CREAS: VÍNCULO EMPREGATÍCIO}

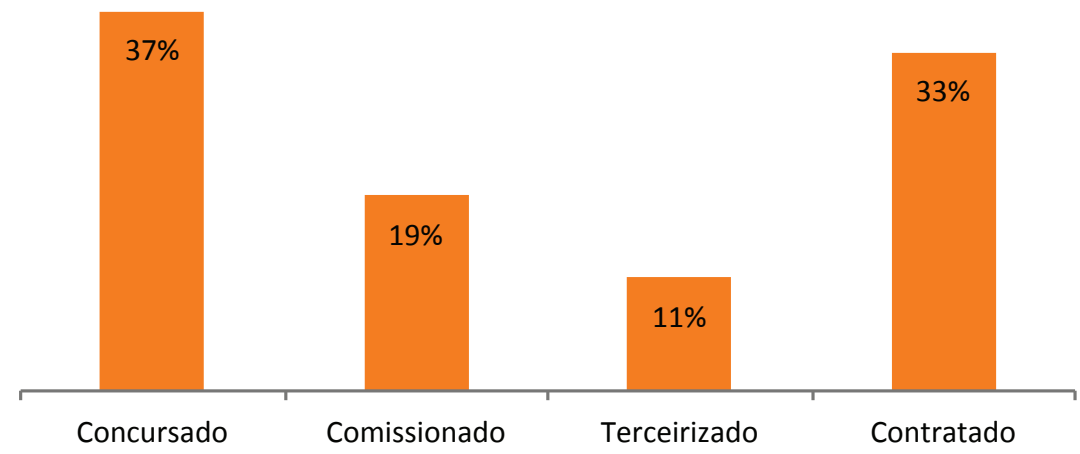

Fonte: IBGE, 2014

Na maior parte dos casos, faltavam banheiros em boas condições estruturais e de limpeza para uso dos beneficiários, bem como bebedouro higiênico com copos. O número de salas de atendimento é por vezes insuficiente e suas condições, precárias (a exemplo salas separadas apenas por divisórias), afetando principalmente a possibilidade de sigilo e privacidade nos atendimentos. A reclamação dos usuários, no entanto, não apontou para a falta de privacidade9, centrando-se na localização dos equipamentos e dificuldades de deslocamento. Em alguns casos, o CREAS divide seu espaço com o Conselho Tutelar, o que, por um lado facilita o trabalho e as articulações, e por outro confunde o usuário quanto às funções de cada órgão. Na maioria dos equipamentos há falta de material informático, como computadores e internet, bem como materiais socioeducativos. Ainda, os carros disponíveis são insuficientes para a demanda, seja pelo compartilhamento com outro serviço municipal, seja pela existência de limite de quilometragem mensal.

8 Por certo, isso não pode ser dito dos Centros de Atenção Psicossocial (Caps), que enfrentam dificuldade similar. Mas, de forma geral, a situação na saúde é inversa, sendo o esforço maior voltado à divulgação dos equipamentos e programas da saúde básica como forma de desafogar o sistema hospitalar-ambulatorial de problemas menos complexos.

9 Há que se ter em conta aqui um possível viés de seleção. Os usuários mais dispostos a participarem dos grupos focais e entrevistas podem ser exatamente os que menos valorizam a questão da privacidade. Os casos e usuários mais sensíveis à questão da privacidade podem ter preferido não participar da pesquisa, ou mesmo se afastado do serviço socioassistencial por este motivo.

Revista Brasileira de Monitoramento e Avaliação | Número 7 | Janeiro-Junho de 2014 


\section{RECURSOS HUMANOS E DEMANDAS DE CAPACITAÇÃO}

Os CREAS pesquisados contam com quadros formados majoritariamente por mulheres (83\%) e altamente qualificados: todas as pessoas entrevistadas tinham curso superior, que destas, 50\% tinham curso de pós-graduação. Com respeito ao vínculo empregatício no Gráfico 3, o quadro do CREAS é formado primeiramente por concursados (37\%), seguido por contratados (33\%), comissionados (19\%) e terceirizados (11\%). Somando-se os valores das categorias que se caracterizam pela "instabilidade" de vínculo (contratados, terceirizados e comissionados), obtém o total de $63 \%$, isto é, mais da metade dos profissionais investigados que atualmente trabalham nos CREAS. Cabe ressaltar que a alta rotatividade dos profissionais do CREAS, problema frequentemente citado nas entrevistas e correlacionado com a fragilidade dos vínculos trabalhistas, prejudica o processo de capacitação - outro ponto problemático, que será abordado a seguir.

Considerando o nível de escolaridade e o número de profissionais existentes em cada CREAS, constata-se que os CREAS visitados respondem bem ao perfil exigido pela NOB-SUAS-RH. Não obstante, observa-se em campo, principalmente em municípios de pequeno porte, a dificuldade em que o CREAS conte com profissionais de direito e com profissional específico para a Proteção Social Especial (PSE), o que gera acúmulo das funções para o coordenador do equipamento (como já apontado, diversos relatos ressaltam o fato de o número de profissionais do equipamento não ser suficiente para suprir a demanda). Além disso, estes profissionais muitas vezes não tinham clareza sobre o papel desempenhado por cada um, vocalizando a necessidade de uma orientação a esse respeito. Ademais, nem sempre a formação acadêmica dos profissionais garante o bom atendimento, uma vez que a formação universitária não os prepara para enfrentar a realidade que se apresenta no CREAS e que, frequentemente, encontra-se defasada frente às novas concepções e normativas da assistência social, cabendo um processo de capacitação para que os serviços tipificados sejam ofertados em conformidade com o ordenamento vigente.

Em suma, há carência de capacitação aos técnicos do CREAS. As demandas por capacitação vocalizadas por eles giram em torno de diversos temas, entre os quais se destacam a política de assistência social e o papel do CREAS no âmbito do SUAS; o papel de cada profissional no âmbito do CREAS; as temáticas específicas enfrentadas pelos profissionais no seu trabalho diário, tais como drogadição e exploração sexual; formas de abordagem para públicos específicos (mulheres, crianças e adolescentes, idosos etc.); os sistemas de garantia de direitos; e aspectos normativos, administrativos e de planejamento. Citou-se ainda a necessidade de capacitação de outras equipes que trabalham com a assistência social, como saúde e educação. Capacitações mais contínuas para atualização constante acerca das políticas foram demandadas, além de sugerir uma apresentação de casos para exemplificar durante as capacitações, haja vista a dificuldade de aplicar estas aos casos que vivenciam no dia a dia do CREAS. 


\section{ORGANIZAÇÃO DOS SERVIÇOS}

1. CREAS em que existe a divisão de equipes por serviço: Paefi, MSE e Abordagem Social;

2. CREAS no qual a equipe das MSE é independente dos demais profissionais que realizam os serviços Paefi e Abordagem Social;

3. CREAS em que a equipe realiza todos os três serviços.

Esta divisão é influenciada pelo porte do município e o tamanho da equipe, mas há também outros elementos que o explicam. No geral, em municípios pequenos, que contam com equipes reduzidas, não há registro de distribuição dos profissionais por serviços. Por outro lado, uma metrópole, por exemplo, optou por não dividir a equipe em programas com o intuito de não fragmentá-la. Em termos numéricos, temos que três casos pertencem ao primeiro grupo (equipes por programa), um caso ao segundo (MSE independente) e cinco casos ao terceiro, com uma mesma equipe respondendo por todos os programas. Um caso apresenta uma situação de mais difícil classificação, pois, apesar do serviço de MSE ter independência e contar com um coordenador específico, é executado pelas técnicas do CREAS.

\section{PAEFI}

Em todos os municípios, a demanda do Paefi é formada, sobretudo, por violações dos Direitos da Criança e Adolescente e do Idoso, citadas pelos técnicos entrevistados como: "abandono e negligência ao idoso", "negligência e aban- dono de incapaz", "violência e negligência contra criança e adolescente", "maus tratos"

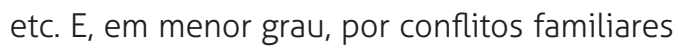
em decorrência do uso de álcool e drogas por algum de seus membros. Esta demanda chega, na maioria dos casos, mediante encaminhamentos realizados pelo Conselho Tutelar, Ministério Público, Defensoria Pública, Delegacias, Juizados ou canais de denúncia, tais como o disque 100. Também foram mencionados encaminhamentos realizados pelos CRAS, Conselhos e secretarias setoriais, principalmente de saúde, e por demanda espontânea. A busca ativa não foi mencionada como meio usual de recebimento da demanda.

O fluxo usual de trabalho no Paefi se divide nas seguintes etapas, com variações a depender do equipamento:

- acolhida e escuta, a partir das quais se verifica quais serão os tipos de atendimento realizados e por quais profissionais;

- atendimento (individual ou em grupo);

- visitas domiciliares para acompanhamento ou para verificação de denúncias;

encaminhamento para outros serviços da rede socioassistencial, em especial para o CRAS, para o sistema de garantia de direitos (Conselho Tutelar, Juizado da Infância e da Juventude, Juizado da Mulher, Promotoria do Idoso e da Pessoa com Deficiência) ou de outras políticas setoriais (principalmente saúde, educação e habitação);

- elaboração de relatórios.

Revista Brasileira de Monitoramento e Avaliação | Número 7 | Janeiro-Junho de 2014 
- QUADRO 3: SÍNTESE DE ATIVIDADES PAEFI

\begin{tabular}{|c|c|}
\hline \multicolumn{2}{|r|}{ QUADRO SÍNTESE PAEFI } \\
\hline TRABALHO SOCIAL & SITUAÇÃO OBSERVADA NOS 10 CASOS \\
\hline Estudo social & Realizado em todos os casos \\
\hline Busca ativa & $\begin{array}{l}\text { Realizado em aproximadamente } 50 \% \text { dos casos, mas, sobretudo, para } \\
\text { verificação de denúncia }\end{array}$ \\
\hline Visitas domiciliares & Realizadas em todos os casos \\
\hline Atendimento psicossocial familiar & Realizado em todos os casos \\
\hline Atendimento psicossocial individual & Realizado em todos os casos \\
\hline Orientação jurídica & $\begin{array}{l}\text { Apenas } 6 \text { municípios contam com profissional do direito, portanto, } \\
\text { não realizada em } 4 \text { casos }\end{array}$ \\
\hline Acesso à documentação pessoal & Realizado em todos os casos \\
\hline Atividades em grupo & $\begin{array}{l}\text { Apenas } 3 \text { municípios contam com atividades coletivas específicas } \\
\text { para o Paefi e nem sempre estão adequadas aos seus objetivos. }\end{array}$ \\
\hline $\begin{array}{l}\text { Referência e Contrarreferência para } \\
\text { Rede }\end{array}$ & $\begin{array}{l}7 \text { casos confirmaram a realização sistemática de referência e contrar- } \\
\text { referência. Poucos/as usuários/as confirmaram terem sido encami- } \\
\text { nhados para CRAS }\end{array}$ \\
\hline $\begin{array}{l}\text { Encaminhamentos para políticas se- } \\
\text { toriais }\end{array}$ & $\begin{array}{l}\text { Considerando as informações dadas pelos profissionais, todos os ca- } \\
\text { sos realizam encaminhamentos. Entretanto, poucos/as usuários/as } \\
\text { afirmaram terem sido encaminhados }\end{array}$ \\
\hline
\end{tabular}

Fonte: DataUFF/ fevereiro de 2014

Os registros são realizados por meio de ficha de acolhimento, ficha de acompanhamento e relatórios, normalmente mantidos em arquivos físicos. Apesar da precariedade existente em alguns equipamentos, é frequente a cooperação entre a equipe, tanto para análise dos casos, como para compartilhamento de informações, divisão de trabalho e planejamento para atendimento dos casos. Os encaminhamentos são realizados, mas há pouca menção ao seu acompanhamento. Em muitas situações, os profissionais dos serviços se organizam por dia, por exemplo: dia para atendimento, dia para visita domiciliar e dia para elaboração de relatórios. As atividades para cada um desses dias preenche todo o tempo disponível de maneira que não há um momento para acompanhar os atendimentos e encaminhamentos já realizados. O acompanhamento se dá normalmente no próximo atendimento agendado, quando, muitas vezes, o profissional é surpreendido com a informação de que o usuário não teve o devido atendimento na instituição para a qual foi encaminhado. Nesse caso, o tempo decorrido prejudica o atendimento eficaz do usuário.

O fluxo para saída do usuário do serviço se verifica quando há superação da violação do direito, constatado pelos profissionais envolvidos no acompanhamento do caso, ou quando não há comparecimento ao atendimento, o que leva os profissionais a realizarem uma visita domiciliar para verificar a razão do não 


\section{OQUADRO 4: SÍNTESE ABORDAGEM SOCIAL}

\begin{tabular}{|c|c|}
\hline \multicolumn{2}{|r|}{ QUADRO SÍNTESE PAEFI } \\
\hline TRABALHO SOCIAL & SITUAÇÃO OBSERVADA NOS 10 CASOS \\
\hline Trabalho social & Situação observada nos 10 casos \\
\hline Estudo social do território & Informal \\
\hline $\begin{array}{l}\text { Abordagem e Busca ativa - pessoas em } \\
\text { situação de rua }\end{array}$ & $\begin{array}{l}\text { Realizados de forma sistemática } 4 \text { casos; } 6 \text { apenas de forma es- } \\
\text { porádica, por denúncia }\end{array}$ \\
\hline Abordagem e Busca ativa - trabalho infantil & Esporádica ou por denúncia em todos os casos \\
\hline $\begin{array}{l}\text { Abordagem e Busca ativa - exploração } \\
\text { sexual comercial }\end{array}$ & Esporádica e ou por denúncia em todos os casos \\
\hline $\begin{array}{l}\text { Trabalho conjunto/definido com Centro } \\
\text { Pop quando exista tal equipamento }\end{array}$ & $\begin{array}{l}\text { Existe fluxo entre dois serviços em todos os casos em que se } \\
\text { têm Centro Pop. Entretanto, não apareceu nos discursos como } \\
\text { um parceiro forte }\end{array}$ \\
\hline Encaminhamentos ao Paefi & Realizados em todos os casos \\
\hline Encaminhamentos às políticas setoriais & Realizados em todos os casos, sobretudo, para saúde \\
\hline Encaminhamentos para sistema de justiça & Realizados em todos os casos quando necessário \\
\hline $\begin{array}{l}\text { Encaminhamentos aos serviços de aco- } \\
\text { lhimento institucional/ república/família } \\
\text { acolhedora }\end{array}$ & $\begin{array}{l}\text { Apenas } 5 \text { casos contam com serviço de acolhimento institucio- } \\
\text { nal no município }\end{array}$ \\
\hline
\end{tabular}

Fonte: DataUFF/ fevereiro de 2014

comparecimento. Caso haja reincidência no não comparecimento, normalmente o profissional encaminha o caso ao sistema de garantia de direitos, para providências cabíveis.

O Quadro a seguir sintetiza as estratégias e ferramentas utilizadas pelos CREAS pesquisados na execução do Paefi:

Conforme o quadro apresentado, o Paefi está relativamente adequado às exigências da Tipificação Nacional dos Serviços Socioassistenciais. Entretanto, na análise dos casos identificou-se alguns desafios tais como: a falta de profissionais de direito; a padronização e consensuamento do fluxo de atendimentos com a Rede Socioassistencial e demais parceiros; a avaliação das estratégias de execução do serviço com melhor cotejamento do perfil de seus usuários em potencial e suas necessidades; e o melhor acompanhamento dos encaminhamentos realizados.

\section{ABORDAGEM SOCIAL (SEAS)}

Este serviço não era ofertado regularmente por todos os CREAS visitados. Nas cidades menores, além de esporádico, o SEAS não tem um público definido, dirigindo-se ao mesmo grupo atendido pelo Paefi e se desenvolvendo mais a partir de verificação de denúncia que por busca ativa, seja pelo número limi-

Revista Brasileira de Monitoramento e Avaliação | Número 7 | Janeiro-Junho de 2014 
tado da equipe técnica, pela falta de veículo ou mesmo pela concepção que se tem do serviço.

Nos municípios maiores, o serviço atua em paralelo, às vezes complementarmente, aos Centros Pop existentes - realidade que alterou a forma de atuação dos CREAS e não pôde ser mais bem observada devido a não inclusão dos Centros POP entre os equipamentos investigados. O SEAS como serviço ofertado diariamente se organiza usualmente em forma de escalas por educadores e componentes da equipe. Apenas o profissional de direito quem acompanha o atendimento. É feita a abordagem de rua, de carro, e ao final alguns usuários acompanham os técnicos do CREAS até o equipamento.

Entretanto, em especial nos municípios de médio e pequeno porte, a concepção do SEAS por vezes se distancia das diretrizes nacionais. Há casos em que não se compreende, por exemplo, que o CREAS tem o papel de trabalhar com a população de rua, sobretudo porque esta seria formada por usuários de drogas. Também se verifica um discurso corrente que nega a existência de trabalho infantil nos territórios de referência. Como consequência, a abordagem se compreende como atividade realizada com o Conselho Tutelar e a Polícia Militar na verificação de denúncias ou busca de situações como prostituição em bares e outros locais públicos. Este SEAS "esporádico", observado em diversos municípios, atua a partir de denúncias feitas pela população ou advindas dos órgãos do siste- ma de garantia de direitos. Muitos casos encontrados estão relacionados ao alcoolismo, aos problemas de saúde mental e adolescentes que fogem de suas famílias. Além disso, foram citados casos de abordagem envolvendo tratamento para pessoas com uso de entorpecente e para solicitação de documentos.

Na maioria dos casos, não há equipe específica para a realização do serviço de abordagem, sendo realizado por todos os profissionais do equipamento. Independente do porte municipal, o SEAS não está orientado por um diagnóstico socioterritorial. Em muitos casos, defende-se que o conhecimento de campo é suficiente para definir os locais de atuação o que significa que o serviço pode se tornar refém de "verdades" construídas pelo senso comum e reforçar estigmas. 0 Quadro 4 apresenta a síntese do serviço tal qual observado em campo.

\section{SERVIÇO MSE}

Este serviço foi recentemente incorporado nos CREAS pesquisados, sendo que em dois casos o processo ainda não se completou. Além dos problemas comuns com os processos de transição, o fato de ser um serviço que atua estreitamente ligado às demandas do Poder Judiciário faz que sua integração ao CREAS tenha maiores dificuldades para se consolidar.

Por mais que as equipes do CREAS interajam cotidianamente nos espaços comuns, as pessoas envolvidas com as MSE tendem a trabalhar de forma isolada. Esse isolamen- 


\section{QUUADRO 5: SÍNTESE MSE}

\section{QUADRO SÍNTESE PAEFI}

\section{TRABALHO SOCIAL}

Trabalho social

Acolhida dos jovens em espaços do Poder Judiciário

Acolhida dos jovens no CREAS

Elaboração do PIA com jovem em cumprimento de medida

Atendimento/acompanhamento Individual

Atendimento/ acompanhamento Familiar

Atendimento em grupo

Encaminhamentos às políticas setoriais

Encaminhamento e acompanhamento do PSC Realizados em todos os casos quando necessário

\section{SITUAÇÃO OBSERVADA NOS 10 CASOS}

Apenas 1 caso

Realizada em todos os casos

Realizada em todos os casos segundo os profissionais entrevis$\operatorname{tados}^{10}$

Realizada em todos os casos, com distinção de periodicidade para LA e PSC

Profissionais afirmam realizá-los; a maioria de usuários diz não ter atendimento familiar

Em aproximadamente $50 \%$ dos casos

Profissionais afirmam realizá-los; a maioria de usuários diz não ter sido encaminhado

Realizada em todos os casos, mas o formato de acompanhamento é distinto

Fonte: DataUFF/ fevereiro de 2014

to influencia inclusive a articulação entre os serviços. Foram poucos os relatos de encaminhamento, por exemplo, de adolescentes em meio aberto ou de algum familiar para os serviços do Paefi, ao contrário do que se verifica com a Abordagem Social.

A análise constata que o serviço de MSE parece se estruturar de forma adequada às exi- gências da Tipificação Nacional dos Serviços Socioassistenciais. De modo geral, as equipes demonstram conhecimento sobre os serviços, sendo que alguns municípios contam com profissionais que têm trajetória antiga na militância das causas da juventude em conflito com a lei, isto é, têm perfil adequado para trabalhar com temas tão delicados. Quanto ao desenvolvimento do serviço, em todas

10 Alguns jovens manifestaram desconhecer do que se trata o PIA. Em alguns casos apenas a nomeação "PIA" era desconhecida, mas em outros verificou-se que os adolescentes não reconheciam ter participado da construção de qualquer plano de atendimento e nem compreendiam exatamente o que eles faziam no espaço do CREAS. Uma vez que o Sinase prevê que o PIA deve contar com a participação efetiva do adolescente e, inclusive, apontar os objetivos declarados por ele próprio, não parece factível que nestes casos um Plano Individual de Atendimento tenha sido de fato posto em prática.

Revista Brasileira de Monitoramento e Avaliação | Número 7 | Janeiro-Junho de 2014 
- FIGURA 1 - REDE DE PARCERIAS CREAS

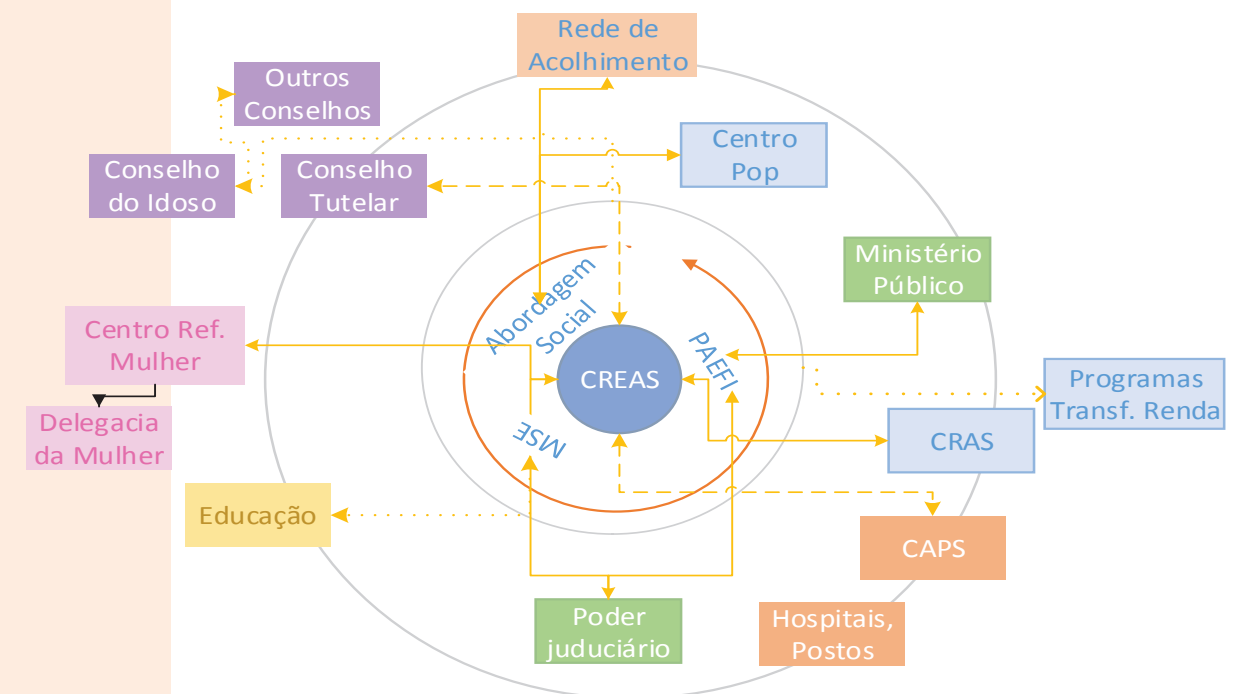

Fonte: DataUFF/fevereiro de 2014

as cidades o processo é similar: o/a jovem é acolhido/a, elabora-se o Plano Individual de Acompanhamento (PIA) com os envolvidos (jovem e responsável) e inicia-se o acompanhamento - que em algumas cidades é individual, em outras, em grupo, e nas duas modalidades em algumas cidades. A diferença está apenas no foco do acompanhamento em decorrência da medida aplicada: acompanhamento escolar (LA) e prestação de serviço à comunidade (PSC).

Há dois principais desafios ao serviço de Medidas Socioeducativas: O primeiro é institucional, pois dada a característica peculiar do serviço, cuja demanda por atendimento e formato de acompanhamento são fortemente regulados pelo Judiciário local, o espaço de ção de serviço de proteção social de média complexidade conforme suas competências se vê contraposto a um modelo de atendimento que torna o CREAS balcão de serviços do Poder Judiciário. O segundo tem relação com a qualidade do atendimento, em especial no que se refere ao acompanhamento mais próximo do cumprimento da medida, das situações que dificultam o seu cumprimento, e do encaminhamento para outros serviços/ políticas setoriais, a partir de cada situação analisada. Observou-se em campo o trabalho de conscientização e acolhida, mas sem que se estabeleça acompanhamento mais qualificado da medida. Os relatos mais frequentes foram de encaminhamento à área de saúde no caso de drogadição ou de reinserção à escola. No caso de descumprimento da medida, normalmente há elaboração de relatório a ser 
encaminhado ao Juizado para providências cabíveis. O Quadro 6 apresenta síntese do serviço tal qual observado em campo.

\section{RELAÇÕES COM A REDE E POLÍTICAS SETORIAIS}

Os CREAS participam de um cenário composto por diferentes atores e formas de relacionamento. Classificando as informações colhidas, verifica-se que mais próximos dos CREAS estão os CRAS, os Conselhos Tutelares e outros órgãos de Justiça (Ministério Público, Defensoria, Poder Judiciário). Em seguida, há um grande fluxo com a saúde e, em menor grau, com a educação. Dialoga-se com outros tantos parceiros, mas com uma intensidade que dependerá de caso a caso, do perfil de usuários em cada cidade e até mesmo da estrutura institucional.

Sobre o tema das articulações, a análise destaca que as ferramentas tradicionais para a realização de encaminhamento (relatórios, ofícios, contato telefônico, visitas à entidade, reuniões com profissionais) são compreendidas como ferramentas de articulação em todos os municípios pesquisados. Na maior parte dos casos é a demanda quem "força" os processos de articulação. Isto significa que não há um planejamento desse processo, embora tanto gestores quanto técnicos reconheçam a importância e a necessidade da articulação e intersetorialidade em todos os espaços de atuação. Da mesma forma, não há acompanhamento mais efetivo nos encaminhamentos realizados: os profissionais entendem a relevância do acompanhamento, mas são suplantados pelas demandas diárias do equipamento.

Existe uma incompreensão quanto aos limites do trabalho do CREAS, em algumas situações inclusive por parte dos profissionais do próprio equipamento ou da rede socioassistencial, e por isso recebe demandas que extrapolam suas atribuições. Esta insuficiente compreensão quanto ao papel do CREAS, somado à ausência de articulações fortes e às dificuldades de se receber retorno quanto aos encaminhamentos realizados geram um sentimento pessimista com relação ao trabalho em rede - visto como complexo, difícil, frágil e distante. Em muitos casos, verifica-se ainda a influência da "pessoalidade" e "intimidade" (nos termos da cordialidade de Sergio Buarque de Holanda ${ }^{11}$ ) no sucesso ou fracasso dos processos de articulação e relação entre os atores. Isto significa que quando se tem algum conhecido no espaço, a articulação acontece de forma mais fácil.

Em suma, o trabalho intersetorial e em rede ainda não funciona como deveria, formalizado e compreendido como dever da coisa pública com o objetivo de garantir um atendimento de qualidade aos usuários. Quando 
identificados, os avanços são considerados resultados da insistência em se trabalhar articulado: respostas imediatas em alguns casos, relações mais favoráveis, retornos positivos e processos que apontam para um maior reconhecimento das competências de cada um dos atores envolvidos no processo.

\section{PERCEPÇÃO SOBRE A OUUALIDADE DOS SERVIÇOS E AOQUISIÇÕES DOS USUÁRIOS}

As avaliações acerca do CREAS e seus serviços possuem, como não poderia deixar de ser, conteúdos e ênfases diversas quando se comparam os discursos dos profissionais e dos usuários. Não obstante, a avaliação geral é positiva e as dificuldades são apontadas dentro deste contexto geral de aprovação do equipamento e das atividades ali proporcionadas.

A percepção dos técnicos sobre a qualidade dos serviços sugere um bom nível de aprovação, mas sempre acompanhado de ressalvas que indicam que "fazem o melhor dentro do possível" e que "necessitam de capacitações" para alcançarem melhores resultados. O CREAS foi mencionado em diversos momentos como um espaço importante de diálogo e de escuta, como fonte de informações sobre direitos e deveres dos cidadãos e de orientações acerca de temas diversos como drogadição e controle de natalidade. Os encaminhamentos dados no CREAS, que possibilitam acesso aos serviços de saúde, aos benefícios e ao Poder Judiciário, foram citados como aquisições importantes proporcionadas pelo equipamento.

Foi apontado pelos profissionais como aquisição proporcionada pelo Paefi aos seus usuários um relacionamento mais harmonioso com a família e o fortalecimento dos vínculos familiares e comunitários; o empoderamento dos usuários; e a conquista da autonomia graças ao retorno ao mercado de trabalho. No caso do serviço de abordagem social, foi citado o resgate da cidadania por meio da emissão de documentos e da saída da rua como local de moradia e a sua saída de uma situação de violação de direitos. A volta do usuário do serviço de abordagem social à sua cidade de origem bem como o abandono de vícios também figuram como um resultado possível dos serviços nos relatos dos profissionais do equipamento. No que tange às aquisições dos usuários das MSE, os profissionais entrevistados foram quase unânimes em relatar que as principais são a volta à escola, a inserção em cursos técnicos e no próprio mercado de trabalho, bem como a melhoria da relação entre pais e filhos, com a família e a sociedade de modo geral, citando também o fato de pararem de cometer atos infracionais.

Já os usuários do Paefi e da Abordagem, participantes dos Grupos Focais, avaliaram bem os serviços recebidos em todas as localidades visitadas, indicando os CREAS como lo- 
cais de referência para se encontrar "apoio", "atenção", "conselhos" e "resolver seus problemas". Como consequência, compreendem que mudanças significativas são obtidas no processo de acompanhamento. Estas não são apenas no sentido material (embora alguns tenham citado a obtenção de algum benefício ou a recuperação de benefício cortado), mas dizem respeito também ao fortalecimento da autoestima e autoconfiança. Em geral, relatam gostar dos serviços principalmente porque podem desabafar e são bem atendidos, independentemente de sua classe social. Às vezes acham distante a localização e afirmam que faltam atividades (como esportes para as crianças e encaminhamentos aos cursos profissionalizantes para os adultos). Como aquisições, foram citadas a amenização de conflitos familiares; a obtenção de informações sobre encaminhamentos legais (por exemplo guarda dos filhos); a mitigação de problemas ligados ao uso abusivo do álcool e outras drogas e a distúrbios emocionais; bem como melhoria das notas escolares.

Deve-se ressaltar que a avaliação positiva dos serviços de Abordagem e do Paefi apareceu diversas vezes nos discursos dos participantes dos Grupos Focais tendo como elemento de comparação o atendimento recebido em outros equipamentos públicos, de saúde e de educação, que é visto por tais participantes como frios e ineficientes.
A maior parte de sugestões diz respeito à divulgação dos serviços e aos aspectos como salas mais reservadas; profissionais de outras áreas disponíveis para atendimento, como psicopedagogo, fonoaudiólogo e psiquiatra; oferta de cursos profissionalizantes (por exemplo corte e costura) e mais eventos.

Os adolescentes em cumprimento de medidas socioeducativas (MSE) atendidos nos CREAS visitados avaliaram de maneira positiva os serviços dos quais são usuários. A relação com os profissionais do Centro foram em geral muito bem avaliadas, especialmente porque eles sentem que não são vistos com preconceito pelo ato que cometeram, ao contrário do que ocorre em outros ambientes, que acabam os estigmatizando. De modo geral, as principais aquisições citadas pelos usuários das MSE foram as mudanças comportamentais, pois declararam estar mais tranquilos, menos "bagunceiros", mais estudiosos e em relação mais harmoniosa com a família, passando agora mais tempo em casa, refletindo acerca do que "fizeram de errado", ao contrário do que antes ocorria.

Entretanto, muitos associam ir ao CREAS como "cumprir um dever" e pela ótica de que devem pagar ou serem castigados pelo erro que cometeram, não compreendendo o serviço para além da alternativa à priva-

Revista Brasileira de Monitoramento e Avaliação | Número 7 | Janeiro-Junho de 2014 
ção de liberdade condicionada aos deveres impostos pelos profissionais que os acompanham. Em diversas entrevistas foi possível perceber que não havia um plano de atividades e acompanhamento dos usuários que fosse claro a estes, evidenciando que, ademais de não saber o que é o Plano Individual de Atendimento, pareciam desconhecer os objetivos das medidas para além de citações vagas de "reintegração à sociedade". Algumas entrevistas apontaram o que, na percepção dos usuários, seriam limites do serviço: falta de acompanhamento ao usuário e à sua família; insuficiência da PSC para "mudar a cabeça do jovem" e afastá-lo do crime; inutilidade da PSC à vida do adolescente, causando "perda de tempo" que poderia ser utilizado para se qualificar profissionalmente, trabalhar e/ou estar em casa; piora nas "cobranças" familiares. De fato, muitos usuários mostraram-se também angustiados com a dificuldade em se conciliar o trabalho com o comparecimento ao CREAS e sugeriram a adequação dos horários das MSE com os horários individuais deles, de escola e trabalho, bem como um número maior de atividades para que não "fiquem de bobeira" - de preferência algo que possa lhes ser útil no mercado de trabalho ou que proporcione acesso à cultura e ao lazer. 


\section{Referências bibliográficas}

BRASIL. Ministério do Desenvolvimento Social e Combate à Fome. Sumário Executivo da Pesquisa sobre a gestão, organização e a implementação dos serviços socioassistenciais desenvolvidos nos Centros de Referência Especializados de Assistência Social (CREAS). Brasília, 2014. Disponível em: <http://aplicacoes.mds.gov.br/sagirmps/simulacao/sum_executivo/pg_principal.php?url=ano_new>.

Microdados do Censo SUAS 2013. Brasília, 2014. Disponível em: <http://aplicacoes. mds.gov.br/sagirmps/simulacao/sum_executivo/pg_principal.php?url=busca_por_id\&id_ sum $=137>$.

Relatório de Resultados do Censo SUAS

2013. Brasília, CGVS/DGSUAS/SNAS/MDS,

2014. Disponível em: <http://blog.mds.gov.br/ redesuas $/ ? p=474>$.
HOLLANDA, S. B. Raízes do Brasil. 4. ed. In: Caminhos e fronteiras. 2. ed. Brasília: Ed. da. UNB, 1963; Rio de Janeiro: J. Olympio, 1975.

INSTITUTO BRASILEIRO DE GEOGRAFIA E ESTATÍSTICA. Perfil dos municípios brasileiros 2005

- Assistência social. Rio de Janeiro, 2006. Disponível em: <ftp://ftp.ibge.gov.br/Perfil_Municipios/>.

Perfil dos municípios brasileiros 2009

- Assistência social. Rio de Janeiro, 2010. Disponível em: <ftp://ftp.ibge.gov.br/Perfil_Municipios/>.

Perfil dos municípios brasileiros 2013

- Assistência social. Rio de Janeiro, 2014. Disponível em: <ftp://ftp.ibge.gov.br/Perfil_Municipios/>.

WORTHEN, B. R.; SANDERS, J. R.; FITZPATRICK, J. L. Avaliação de programas: concepções e práticas. São Paulo: Editora Gente, 2004. 